\title{
Appendicitis in pregnancy: a novel approach for diagnostic dilemma
}

\author{
Atul K Sharma ${ }^{1}$, Rakesh K Sharma ${ }^{2}$, Santosh K Sharma ${ }^{3}$ \\ Sri Lanka Journal of Obstetrics and Gynaecology 2012; 34: 6-10
}

\begin{abstract}
Background: The preoperative diagnosis of acute appendicitis is often inaccurate in pregnant women, and complicated appendicitis is associated with a high rate of fetal loss.
\end{abstract}

Objective: Our purpose was to elicit a better understanding of the presentation of acute appendicitis in pregnancy and to clarify diagnostic dilemmas reported in the literature.

Study design: We retrospectively reviewed 15216 deliveries from June 2009 to December 2011. Selected records were reviewed for gestational age, signs and symptoms at presentation, complications and, histologic diagnosis of appendicitis.

Results: Of 15216 deliveries, 15 (0.1\%) were complicated by a preoperative diagnosis of probable appendicitis. Acute appendicitis was confirmed histologically in 12 (80\%) of the 15 cases. Right-lower-quadrant pain was the most common presenting symptom regardless of gestational age (first trimester [100\%]; second trimester, [80\%]; and third trimester, [60\%]). The mean maximal temperature for proven appendicitis was $37.6^{\circ} \mathrm{C}$, in comparison with $37.8^{\circ} \mathrm{C}$ (not significant) for those with normal histologic findings. The mean leukocyte count in patients with proven appendicitis was 16.4 $\times 10^{9} / \mathrm{L}\left(8.2-27.0 \times 10^{9} / \mathrm{L}\right)$, in comparison with $14.0 \times 10^{9} / \mathrm{L}\left(5.9-25.0 \times 10^{9} / \mathrm{L}\right)$ for patients with normal histologic findings. At the time of surgery, appendiceal perforation was found in 2 cases.

Conclusion: Pain in the right lower quadrant of the abdomen is the most common presenting symptom of appendicitis in pregnancy

\footnotetext{
${ }^{1}$ Senior Resident, Department of General Surgery,

${ }^{2}$ Associate Professor, Department of General Surgery,

${ }^{3}$ Senior Demonstrator, Department of Biochemistry, Government Medical College, Kota, India.

Correspondence: Atul K Sharma

E-mail:docatul83@gmail.com
}

regardless of gestational age. Fever and leucocytosis are not clear indicators of appendicitis in pregnancy.

Key words: appendicitis in pregnancy, pain location, leukocytosis.

\section{Introduction}

Appendectomy for presumed acute appendicitis is the most common non-obstetric surgical emergency during pregnancy, occurring in 1 in 766 births. This represents an overall incidence of $0.05 \%$ to $0.07 \%$ and does not appear to be any different in the nongravid population $^{1,2}$. One report of a reduced incidence of appendicitis during pregnancy suggested a possible protective effect and the mean age is 28 years $^{3}$. Remarkably, the preoperative diagnosis is incorrect in $25 \%$ to $50 \%$ of patients for several reasons ${ }^{4,5}$. Although it can occur in any trimester, there appears to be a slight predominance in the second trimester, with incidences of approximately 30\%, 45\%, and 25\% in the first, second, and third trimesters, respectively ${ }^{6}$. Diagnosing appendicitis is an emergency because it is a potentially life-threatening process for both the mother and may also affect the fetus with preterm labour and delivery. Diagnostic criteria in nonpregnant women cannot be applied in pregnant women because of the changes in anatomy and physiology. Signs and symptoms which are common to both normal pregnancy and appendicitis include anorexia, nausea and vomiting, mild to moderate leucocytosis, and pain. These ultimately lead to diagnostic dilemma for appendicitis in pregnancy.

Uncertainty in making the diagnosis can contribute to delay in surgical intervention with increased maternal and fetal morbidity and mortality rates. The low diagnostic accuracy rate for appendicitis in pregnancy has been accepted as a consequence of an aggressive surgical strategy to minimise the risk of maternal mortality and fetal loss associated with ruptured appendicitis resulting from delayed diagnosis di, $^{7,8}$.

\section{Objective}

The objective of the study was to elicit a better understanding of the presentation of acute 
appendicitis in pregnancy and to clarify diagnostic dilemmas reported in the literature.

\section{Material and method}

All pregnant patients delivered at J K Lone Hospital Kota (India) and in private nursing home and hospitals in the Kota city from June 2009 to December 2011 were reviewed. Records that were coded as "rule out appendicitis" or "appendicitis" were selected. In addition, all patients who had an exploratory laparotomy performed were screened to ensure the greatest possible data accuracy. Data gathered from these records included the presenting complaints, gestational age at presentation, history, physical examination, laboratory evaluation, temperature and operative findings and histopathological examination. Outcome variables included preterm labour, preterm delivery, abruptio placentae, sepsis, appendiceal rupture, and neonatal death.

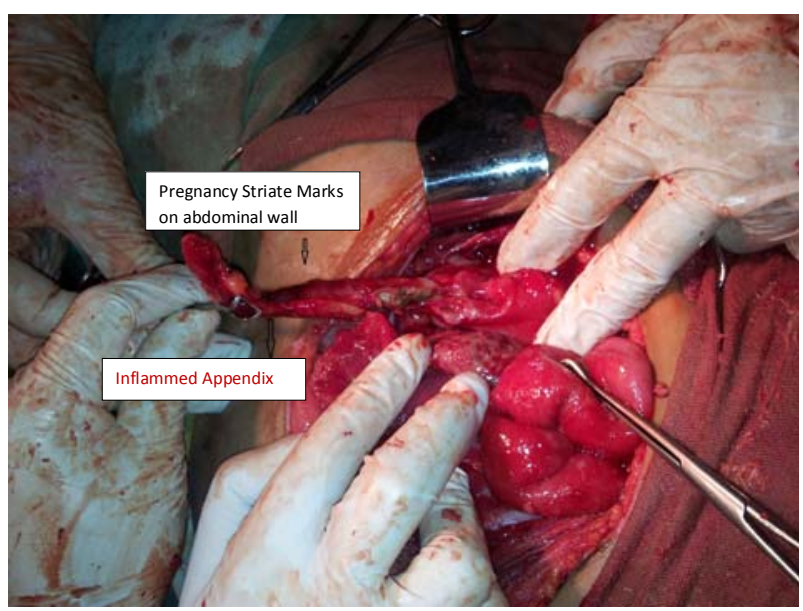

Figure 1. Inflammed appendix in a pregnant woman.

\section{Results}

There were 15216 deliveries during the 2 and half year study period; $15(0.1 \%)$ had a preoperative diagnosis of probable appendicitis. Acute appendicitis was confirmed histologically in $12(80 \%)$ of the 15 women. Distribution of suspected appendicitis in pregnancy was as follows: first trimester, 3 cases $(20 \%)$; second trimester, $6(40 \%)$; and third trimester, $6(40 \%)$.

Pain in the right lower quadrant of the abdomen was the most common presenting symptom regardless of gestational age: $2(100 \%)$ of 2 cases, 4 (80\%) of 5 cases and $3(60 \%)$ of 5 cases in the first, second, and third trimesters, respectively (Table 1), were histologically proven appendicitis amongst the suspected cases of appendicitis. The false-positive rate was $20 \%$ (3 out of 15). Other locations of pain included the left lower quadrant, mid abdomen, epigastric region, and a combination of locations. The mean maximal temperature for proven appendicitis was $37.6^{\circ} \mathrm{C}\left(35.5^{\circ} \mathrm{C}-39.4^{\circ} \mathrm{C}\right)$, in comparison with $37.8^{\circ} \mathrm{C}$ $\left(36.7^{\circ} \mathrm{C}-38.9^{\circ} \mathrm{C}\right.$; not significant) for those with normal histologic findings (Table 2). The mean leukocyte count in patients with proven appendicitis was $16.4 \times 10^{9} / \mathrm{L}$ $\left(8.2-27.0 \times 10^{9} / \mathrm{L}\right)$, in comparison with $14.0 \times 10^{9} / \mathrm{L}$ $\left(5.9-25.0 \times 10^{9} / \mathrm{L}\right)$ for patients with normal histologic findings (Table 3$)$. The mean maximal temperature did not show a statistically significant difference and therefore did not help in distinguishing true appendicitis.

At the time of surgery, appendiceal perforation was found in 2 cases (13\%). One delivery occurred in the postoperative period complicated by abruptio placentae.

Table 1. Pain location by gestational age in histologically proven cases

\begin{tabular}{|c|c|c|c|c|}
\hline \multirow[b]{2}{*}{ Estimated gestational age (wks.) } & \multirow[b]{2}{*}{ Patients (No.) } & \multicolumn{3}{|c|}{ Location of pain } \\
\hline & & $\begin{array}{c}\text { Right upper } \\
\text { quadrant }\end{array}$ & $\begin{array}{c}\text { Right lower } \\
\text { quadrant }\end{array}$ & Other \\
\hline 0-12 (1st trimester) & 2 & 0 & 2 & 0 \\
\hline $12-24$ (2nd trimester) & 5 & 1 & 4 & 0 \\
\hline$>24 \quad$ (3rd trimester) & 5 & 2 & 3 & 0 \\
\hline
\end{tabular}


Table 2. Mean maximal temperature

\begin{tabular}{lccc}
\hline Histological finding & Mean maximal temperature $\left({ }^{\circ} \mathrm{C}\right)$ & \multicolumn{2}{c}{ Temperature $>37.8^{\circ} \mathrm{C}$} \\
\cline { 3 - 4 } & & Number & Percentage \\
\hline Normal & 37.8 & $2 / 3$ & 66 \\
Abnormal & 37.6 & $7 / 12$ & 58.3 \\
\hline
\end{tabular}

Table 3. Mean leukocytosis in all cases

\begin{tabular}{lccc}
\hline Histological finding & Mean leukocytes count $\left(\mathrm{X} 10^{9} / \mathrm{L}\right)$ & \multicolumn{2}{c}{$\begin{array}{c}\text { Patients with leukocyte } \\
\text { count }>15 \times 10^{9}\end{array}$} \\
\cline { 3 - 4 } & & Number & Percentage \\
\hline Normal & 14 & $2 / 3$ & $67 \%$ \\
Abnormal & 16.8 & $5 / 12$ & $42 \%$ \\
\hline
\end{tabular}

\section{Discussion}

In our pregnant population the incidence of appendicitis is slightly higher than in an age-matched group of nonpregnant women described in the surgical literature. The proven incidence of acute appendicitis is similar in pregnant and nonpregnant women ${ }^{1,2}$.

The most common presenting symptoms for appendicitis in pregnancy include anorexia, nausea, vomiting, and right lower quadrant pain ${ }^{5,9}$. Fever and tachycardia may not be present during pregnancy ${ }^{9}$. It is long held belief that the appendix changes its location during pregnancy with an upward displacement toward the costal margin in the later stages of pregnancy ${ }^{10,11}$. Obstetrics teaching historically for $\sim 70$ years has been that the pain of appendicitis migrates upward with the growing uterus; thus pain in the right upper quadrant of the abdomen would be expected in the third trimester. This concept was based on studies that described changes in appendiceal location as pregnancy progresses. Barium studies, performed in 78 women, showed that the growing uterus pushes the appendix upward and with a counterclockwise rotation of the tip. Theoretically, this would change the location of perceived pain toward the right upper quadrant or right flank with advancing gestational age. It is important to note that there is no one reliable sign or symptom that can aid in the diagnosis of appendicitis in pregnancy, and the classic signs of appendicitis such as positive Rovsing's and psoas sign have not been shown to be of any clinical significance in diagnosing an acute appendicitis in pregnancy ${ }^{12}$.

Location of pain: an important predictor: Oto A et al (2006) and Pates JA (2009) concluded the pain of appendicitis radiates with advancement of gestational from right lower quadrant to right upper abdomen ${ }^{13,14}$.

As far as our study is concerned on contrary to long held belief of migration of pain in appendicitis in pregnancy, pain remain localised to right lower abdomen in majority of patients regardless of gestational age (Table 1). As the appendix becomes obstructed by a coprolith, it distends and visceral afferent nerves are stimulated, causing constant poorly localised pain starting near the umbilicus and eventually migrating to McBurney's point, which overlies the location of the appendix in most nompregnant patients. As the full thickness of the appendiceal wall becomes necrotic and the serosa is damaged, the somatic neurons are stimulated, which localises the pain to the right lower quadrant. This process appears to remain similar in pregnancy, contrary to the classical teaching.

Accurate diagnosis of appendicitis in pregnancy can be a diagnostic dilemma, with an accepted falsepositive rate of $\sim 15 \%$. In pregnancy the diagnosis is 
made even more difficult by the growing uterus, leading to inappropriate delay in making the correct diagnosis. The reluctance to operate in pregnancy adds to delay.

The objective of this study was to assess the classic signs and symptoms of acute appendicitis to determine their applicability in pregnancy.

Imaging studies: an aid to diagnosis: Traditionally what does this mean? has shown to be highly sensitive and specific although to a lesser degree after a gestational age of 35 weeks due to technical difficulties ${ }^{15}$. Though ultrasound is rarely helpful in making a diagnosis of acute appendicitis it helps in excluding other pathology like right ovarian or adnexal disease ${ }^{16}$. As far as imaging studies are concerned imaging of the appendix using helical computed tomography has recently shown to be a safe and potentially reliable tool to accurately identify appendiceal changes in appendicitis. Radiation exposure using this test is $300 \mathrm{mrad}$, which is below an accepted safe level of radiation exposure in pregnancy of 5 rad. Reliance on radiographic studies may not be cost-effective, and may deter from careful and timely serial physical exams ${ }^{17}$. MRI can be extremely helpful but operator dependant, expensive and time consuming ${ }^{16}$.

Mean maximal temperature: In our study there was no distinguishing temperature that separated true appendicitis from suspected cases turned out to be falsely positive. $66 \%$ of the patients with normal histology of appendix have mean maximal temperature more than $37.8^{\circ} \mathrm{C}$ while $58.3 \%$ patients having abnormal histology of appendix also have the same temperature (Table 2).

Leukocytosis: The incidence of leukocytosis was slightly higher in acute appendicitis, but the overlap was substantial and negates the value of this laboratory test in reducing false-positive cases and possibly avoiding laparotomy.

Our data support the concept that the majority of patients with acute appendicitis in pregnancy have pain in the right lower quadrant nearly in all trimesters. We could not demonstrate a difference between the histologically proven cases of appendicitis and the "pretenders". Early surgical intervention, with less than a 24-hour delay, has shown to be vital in minimising both maternal and fetal morbidity and mortality. Surgical delays of more than 24 hours from the time of presentation have been associated with appendiceal perforation and significant fetal loss and cases of maternal mortality ${ }^{9,18}$. Use of antibiotic during or after surgery may expose the developing fetus to potential teratogenic substances ${ }^{19}$. Pregnancy related pharmacodynamic changes result in reduced maternal plasma levels of antibiotics ${ }^{20}$. If perforation, peritonitis, or gangrenous appendix has occurred, broad-spectrum antibiotics with anaerobic coverage such as the secondgeneration cephalosporin would be appropriate ${ }^{21}$.

Approach to diagnosis:

- If a pregnant patient comes with pain in right iliac fossa with clinical signs of appendicitis always have a high degree of suspicion to avoid unacceptable delay, with the possibility of increased morbidity and mortality rates.

- Laboratory investigations add little to diagnosis. There may not be leukocytosis and or elevated body temperature.

- In the first trimester or early second trimester consider pelvic ultrasound first, especially if the differential includes adnexal pathology.

- If second (especially late) or third trimester consider going straight to CT scan since this is more helpful and easier to interpret than an MRI.

\section{Conclusion}

The accurate diagnosis of appendicitis during pregnancy requires a high level of suspicion and clinical skills, and not merely relying on the classic signs and diagnostic testing. Early surgical intervention is essential. Our data demonstrate that pain in right lower abdomen is the most common symptom of appendicitis in pregnancy regardless of gestational age. Temperature is not reliably elevated in pregnant patients, and leukocytosis is present but cannot be used to rule out acute appendicitis. It remains to be determined which diagnostic test is best suited to facilitate or determine a diagnosis of acute appendicitis in pregnancy and often the correct diagnosis is determined only at surgical intervention. If in doubt after relevant investigations but have strong clinical suspicion we should go for appendicectomy preferably laparoscopically if feasible.

\section{Acknowledgement}

We are thankful to Dr. R. P. Rawat (Professor and Head of the Department of Gynaecology and Obstetrics) and Dr. Naresh Rai (Professor Department of Pathology) for their valuable support in preparing this manuscript.

\section{References}

1. Tracey M, Fletcher HS. Appendicitis in pregnancy. Am Surg 2000; 66: 555-9: discussion 559-60. 
2. Liu C, McFadden D. Acute abdomen and appendix. In: Surgery: Scientific Principles and Practice, 2nd ed. Edited by Grennfield L, Mulholland M, Oldham K. Philadelphia: Lippincott-Raven 1997; 1246-61.

3. Anderson RE, Lambe M. Incidence of appendicitis during pregnancy. Int J Epidemiol 2001; 30: 1281-5.

4. Andersen B, Nielsen TF. Appendicitis in pregnancy: diagnosis, management and complications. Acta Obstet Gynecol Scand 1999; 78: 758-62.

5. Hée P, Viktrup L. The diagnosis of appendicitis during pregnancy and maternal and fetal outcome after appendectomy. Int J Gynaecol Obstet 1999; 65: 129-35.

6. Babaknia A, Parsa H, Woodruff JD. Appendicitis during pregnancy. Obstet Gynecol 1997; 50: 40-4.

7. Babler AE. Perforative appendicitis complicating pregnancy. JAMA 1908; 51: 1310-13.

8. McGee TM. Acute appendicitis in pregnancy. Aust NZJ Obstet Gynaecol 1989; 29: 378-85.

9. Tamir IL, Bongard FS, Klein SR. Acute appendicitis in the pregnant patient. Am J Surg 1990; 160: 571- 6.

10. Baer J, Reis R, Arens R. Appendicitis in pregnancy with changes in position and axis of normal appendix in pregnancy. JAMA 1932; 98: 1359.

11. Nathan L, Huddleston JF. Acute abdominal pain in pregnancy. Obstet Gynecol Clin North Am 1995; 22: 55-68.
12. Al-Mulhim AA. Acute appendicitis in pregnancy: a review of 52 cases. Int Surg 1996; 81: 295-7.

13. Oto A, Srinivasan PN, Ernst RD, et al. Revisiting MRI for appendix location during pregnancy. AJR Am J Roentgenol 2006; 186: 883.

14. Pates JA, Avendanio TC, Avendiano TC, et al. The appendix in pregnancy: confirming historical observations with a contemporary modality. Obstet Gynecol 2009; 114: 805.

15. Israel GM, Malguria N, McCarthy S, Copel J, Weinreb J. MRI vs. ultrasound for suspected appendicitis during pregnancy. J Magn Reson Imaging 2008; 28 (2): 428-33.

16. Ashmead GG, Katz D. Appendicitis in pregnancy: clinical and imaging update. The Female Patient 2011; 36: 24-9.

17. Old J, Dusing R, Yap W, Dirks J. Imaging for suspected appendicitis. Am Fam Phys 2005; 71: 71-8.

18. Horowitz MD, Gomez GA, Santiesteban R, Burkett G. Acute appendicitis during pregnancy - diagnosis and management. Arch Surg 1985; 120: 1362-7.

19. Stone K. Acute abdominal emergencies associated with pregnancy. Clin Obstet Gynecol 2002; 45: 553-61.

20. Niebyl JR. Antibiotics and other anti-infective agents in pregnancy and lactation. Am J Perinatol 2003; 20: 405-14.

21. Musselman RC, Nunnelee JD, Ware DB. Appendicitis during pregnancy. Clin Excell Nurse Pract 1998; 2: 338-42. 